\title{
Педагогические условия формирования профессионально-педагогической культуры преподавателя СПО аграрного профиля
}

\author{
Любимова Н.И., Никулина Н.Н. \\ Белгородский государственный аграрный университет им. В.Я. Горина \\ Россия, 308500, Белгородская обл., Белгородский район, п. Майский, улица Вавилова, 1 \\ E-mail: Lybimova.1979@mail.ru; nikulina_n@bsu.edu.ru
}

\begin{abstract}
Аннотация. Потребность в профессионально подготовленных кадрах педагогов-аграриев для учреждений среднего профессионального образования аграрного образовательного кластера постоянно растет. Однако остается недостаточно исследованной проблема выбора педагогических условий для успешного формирования профессионально-педагогической культуры будущих педагогов-аграриев. Данные тестирования, опроса и анкетирования свидетельствуют о том, что в совершенствовании и развитии нуждаются все компоненты профессионально-педагогической культуры педагога-агрария - мотивационный, аксиологический, профессиональнопедагогический, технологический, культурологический и коммуникативный. Результаты исследования показали наиболее оптимальные условия: 1) создание педагогической среды для формирования профессионально-педагогической мотивации и ценностного отношения к профессии педагога профессионального обучения; 2) включение студентов в систему практикоориентированного обучения на основе контекстного подходя, позволяющего формировать компоненты профессионально-педагогической культуры в процессе учебной, квазипрофессиональной и профессиональной деятельности; 3) ознакомление студентов с основами герменевтического подхода в педагогике и привлечение их к взаимодействию с педагогами и студентами факультета среднего профессионального образования университета на основе взаимного понимания и эмпатии.
\end{abstract}

Ключевые слова: компоненты профессионально-педагогической культуры, аграрный вуз, среднее профессиональное образование, педагог-аграрий, взаимодействие, педагогическая среда, практико-ориентированное обучение, герменевтический подход.

Для цитирования: Любимова Н.И., Никулина Н.Н. 2020. Педагогические условия формирования профессионально-педагогической культуры преподавателя СПО аграрного профиля. Вопросы журналистики, педагогики, языкознания, 39 (3): 419-431. DOI 10.18413/2712-7451-2020-39-3-419-431

\section{Pedagogical conditions for the formation of Professional and Pedagogical Culture of a Teacher of agricultural vocational training}

\author{
Natalya I. Lubimova, Natalya N. Nikulina \\ Belgorod State Agrarian University V.Ya. Gorina \\ 1 Vavilov St, Village Mayskiy, Belgorod district, Belgorod region, 308500, Russia \\ E-mail: Lybimova.1979@mail.ru; Nikulina@bsu.edu.ru
}

\begin{abstract}
The need for professionally trained staff of agricultural teachers for secondary vocational education institutions in the agricultural educational cluster of the Belgorod region is constantly growing. However, the problem of choosing pedagogical conditions for the successful formation of professional and pedagogical culture of future agricultural teachers in the course of their training remains
\end{abstract}


insufficiently studied in pedagogical theory and University practice. The purpose of this study is to solve this problem. The results of testing, survey and questionnaire indicate that all components of the professional and pedagogical culture of an agricultural teacher - motivational, axiological, professional and pedagogical, technological, cultural and communicative - need to be improved and developed. Experimental data, literature research, and generalization of practical experience have shown that three conditions are the most optimal: 1) creating a pedagogical environment for the formation of professional and pedagogical motivation and value attitude to the profession of a teacher of professional training; 2) the inclusion of students in practice-based learning based on contextual approach, enabling to form the components of professional pedagogical culture in the process of educational, quasiprofessional and professional activities; 3) familiarizing students with the basics of the hermeneutic approach in teaching and engaging them to interact with teachers and students of the faculty of secondary vocational education on the basis of mutual understanding and empathy.

Keywords: components of professional and pedagogical culture, agricultural University, secondary vocational education, agricultural teacher, interaction, pedagogical environment, practice-oriented training, hermeneutical approach.

For citation: Lubimova N.I., Nikulina N.N. 2020 Pedagogical Conditions for the formation of Professional and Pedagogical Culture of a Teacher of Agricultural Vocational Training. Issues in Journalism, Education, Linguistics, 39 (3): 419-431 (in Russian). DOI 10.18413/2712-7451-2020-39-3-419-431

\section{Введение}

Центр аграрного образовательного кластера 31 региона - ФГБОУ ВО «Белгородский государственный аграрный университет им. В.Я. Горина» (БелГАУ). В кластер входят более 10 учреждений среднего профессионального образования (СПО) [Никулина, 2018]. В школах области создаются аграрные классы. Потребность в профессионально подготовленных кадрах педагогов-аграриев обеспечивает кафедра профессионального обучения и социально-педагогических дисциплин БелГАУ. Основную задачу специалисты видят в формировании профессионально-педагогической культуры педагога-агрария.

Вопросы, касающиеся профессионально-педагогической культуры педагога и ее формирования, рассматривались в трудах таких учёных, как Б.М. Бим-Бад [2017], В.А. Веденяпина [2003], И.Ф. Исаев [2002; 2004] и др. Профессионально-педагогическая культура педагога - это сложное образование, которое «представляет собой единство педагогических ценностей, технологий, сущностных сил личности, направленных на ее творческую самореализацию в разнообразных видах педагогической деятельности» [Исаев, 2002, с. 20]. «Человек педагогический» является олицетворением «профессионального самосознания педагога-профессионала» [Батракова, 2004, с. 96].

Выделим те компоненты профессионально-педагогической культуры, без которых невозможно представить себе «человека педагогического» (рис. 1).

Необходимо создать в вузе педагогические условия, в которых может быть сформирована профессионально-педагогическая культура у студентов, обучающихся по направлениям аграрного профиля. Изучению педагогических условий посвящен ряд работ: В.И. Андреева [2012], Н.М. Борытко [2006] и др.

Педагогические условия - это результат «целенаправленного отбора, конструирования и применения элементов содержания, методов (приемов), а также организационных форм обучения для достижения ... целей» [Андреев, 2012, с. 17].

Цель настоящего исследования - определить основные педагогические условия, которые будут способствовать интенсивному формированию профессиональнопедагогической культуры будущих педагогов СПО во всех ее компонентах, помогут вооружить их действенными средствами организации учебно-воспитательного процесса, будут направлены на формирование личности педагога, способного адаптироваться к любым условиям осуществления педагогического процесса. 


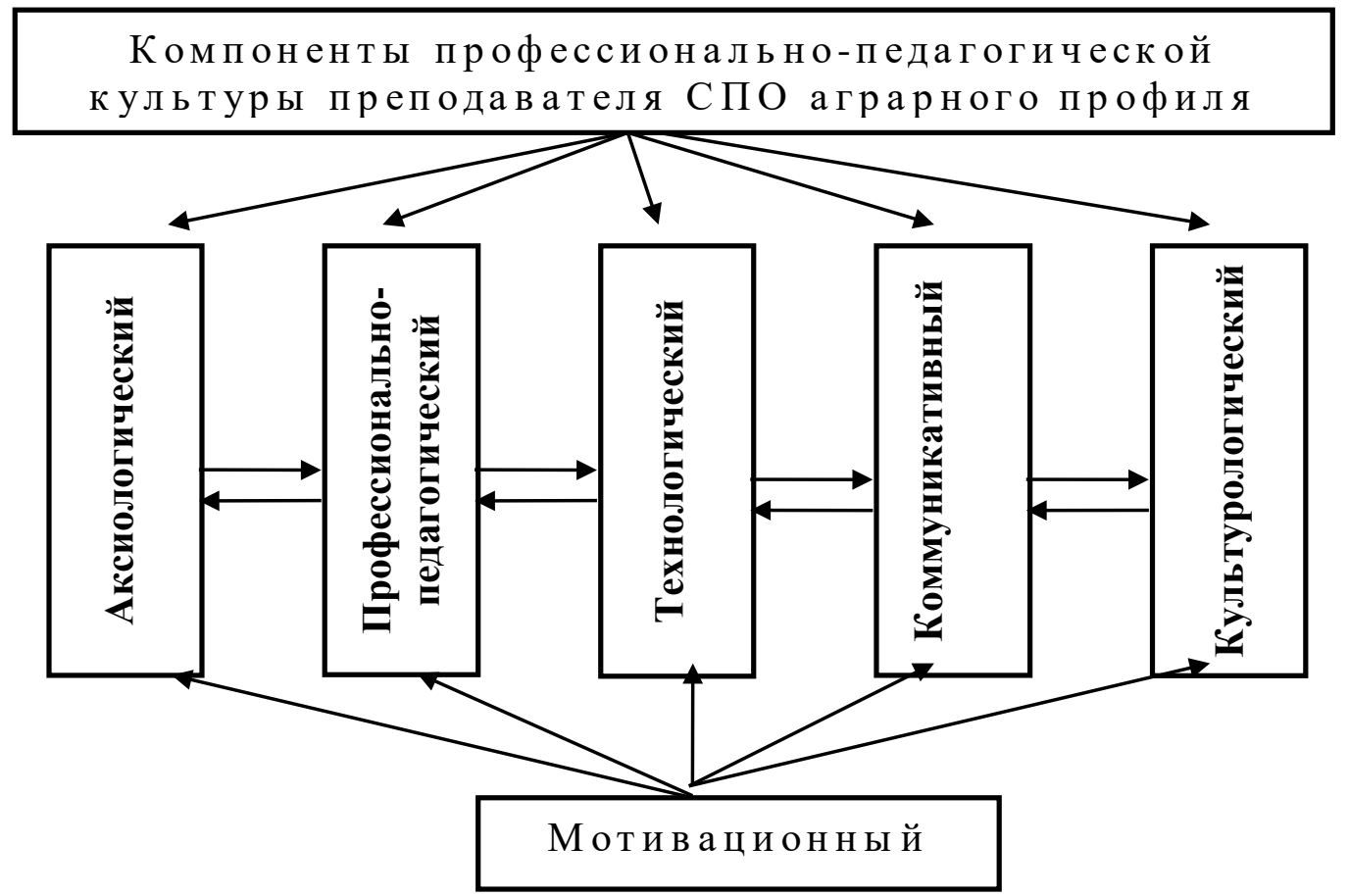

Рис. 1. Компоненты профессионально-педагогической культуры преподавателя СПО аграрного профиля

Fig. 1. Components of the professional and pedagogical culture of a teacher of secondary vocational education in an agricultural profile

\section{Теоретические основы и методика исследования}

Для выяснения мотивационных и ценностных (аксиологических) установок студентов, поступивших в университет на факультет, предполагающий получение специальности педагога-агрария, проведено анкетирование, тестирование и опрос.

На вопрос «Почему вы выбрали наш вуз?» в 70 \% случаев были получены ответы: «Хочу получить высшее образование», «Хочу продолжить обучение» и тому подобные; 10 \% абитуриентов назвали профессии аграрного профиля, которые хотели бы получить, и только 20 \% выразили желание в аграрном вузе получить педагогическую специальность.

Отметим преобладание учебно-образовательных мотивов [Путивцев, 2012] у студентов первого курса, поскольку опыта профессиональной работы у них нет, а также отсутствие интереса к педагогической профессии в подавляющем большинстве.

С целью изучения ценностно-смысловой сферы личности молодого человека, поступившего в вуз аграрного профиля, было проведено тестирование студентов направления подготовки 44.03.04 - Профессиональное обучение (по отраслям), направленность (профиль) «Сельское хозяйство - технология производства и переработки сельскохозяйственной продукции» 38 ПрПО и 36 ТПО групп (48 человек) по системе М. Рокича [Rokeach, 1968].

Исследование ценностных ориентаций показало, что материально обеспеченная жизнь занимает с 1-й до 5-й позиции, а интересная работа - с 10-й до 15-й позиции. Неожиданностью для нас стало то, что впервые за несколько лет исследования 45 \% первокурсников на 1-3 место поставили такую ценность, как «свобода», в то время как не только работа, но и «активная деятельная жизнь», «продуктивная жизнь» заняли с 10-й по 17-ую позиции. В самом конце списка необходимых ценностей оказались «красота природы и искусства», а также «счастье других», понимаемое как «благосостояние, развитие и совершенствование других людей, всего народа, человечества в целом», - ценности, без принятия которых немыслима личность настоящего педагога. 


\section{Результаты и их обсуждение}

Анализ результатов тестирования, компонентов профессионально-педагогической культуры преподавателя СПО аграрного профиля, личного опыта подготовки специалистов данного профиля, изучение и обобщение опыта, описанного в специальной литературе, позволили нам выделить оптимальные условия, достаточные для того, чтобы процесс формирования всех компонентов профессионально-педагогической культуры стал успешным. Эти условия должны способствовать формированию следующих личностных качеств будущих специалистов:

1) мотивационной сферы и ценностных установок (мотивационный, аксиологический и культурологический компоненты);

2) профессиональной компетентности (профессионально-педагогический и технологический компоненты);

3) профессионально-коммуникативной компетентности (коммуникативный компонент).

Изучение учебного процесса по подготовке педагогов аграрного профиля, наблюдение за профессиональным ростом студентов, получающих соответствующую специальность, привели нас к выводу о целесообразности включения в систему подготовки студентов следующих педагогических условий.

1. Создание среды для развития не только личностной, но и профессиональной мотивации, для выработки не только личных, но и профессиональных мотивов, продиктованных как личностными, так и образовательными, культурологическими и профессиональными ценностными установками в соответствии с требованиями государственных стандартов высшего и среднего спещиального образования.

Мотивация процесса учения и профессионального становления изучалась целым рядом ученых: А.А. Вербицкий [2000; 2004], Э.Ф. Зеер [2015], А.К. Маркова [1996] и др.

Цель вуза - сформировать профессионально значимые мотивы учения в вузе через приобретение студентами некоторого профессионального опыта в процессе обучения, поскольку «вход в профессию начинается с решения вопроса о профессиональном самоопределении» [Путивцев, 2014, с. 114], а также развить у студентов потребность в приобретении профессионально значимых педагогических знаний, умений и навыков.

Регулятором поведения личности, направленного на выбор стратегии образования, на формирование личностного мотивационно-ценностного отношения [Драгунова, 2012] к будущей профессии являются ценностные ориентации и ценностные отношения (В.Г. Алексеев, Б.Г. Ананьев, А.Г. Асмолов, Е.С. Волков, Б.Ф. Ломов, Р.С. Немов, С.А. Рубинштнйн, В.А. Сластенин и др.). Именно они выполняют мотивационную функцию и способствуют выбору ведущей деятельности.

Самоактуализация личности в профессии, обретение адекватного к ней отношения - основные мотивационные компоненты становления специалиста-профессионала. Особую ценность приобретает процесс осознания студентом себя как личности, способной к самопроявлению в определенной сфере деятельности, самоутверждению и самореализации в этой сфере. Следовательно, кроме формирования ценностного отношения к педагогическому труду, ценностям педагогической профессии и профессиональной социализации, необходимо приобщение первокурсников к ценностям общечеловеческого характера: труду, активной жизненной позиции, заботе о ближнем, созиданию новых ценностей. По мнению Jukka Husu, одной из личностных ценностей, свидетельствующих о готовности педагога к практической деятельности, является умение «думать собственными мозгами» (“think with our own brains”) [Husu, 2004]. Это определило направленность курсов психолого-педагогического характера, с которыми студенты знакомятся в первые годы обучения в университете. 
В связи с поставленными задачами были перестроены такие курсы, как «Введение в социально-педагогическую деятельность» (1 курс), «Педагогическое мастерство» (1 курс), «Психология профессиональной деятельности» (2 курс), «Моделирование психолого-педагогической деятельности» (3 курс). Направленность этих курсов - формирование интереса к профессии педагога СПО аграрного профиля; формирование ценностного отношения к педагогическому труду, профессии педагога; коррекция ценностных ориентаций через анализ и направленную деятельность как ценностей-целей (терминальные ценности), так и ценностей-средств (инструментальные ценности).

Курс «Ведение в социально-педагогическую (педагога СПО аграрного профиля) деятельность» направлен на формирование у студентов представления о сущностной ценности педагогической деятельности, ознакомление с ценностным характером педагогического труда, с собственно педагогическими ценностями, которые реализуются через педагогический процесс в ссузах и вузах аграрного профиля. Желательно сделать это практически полезно через посещение занятий ведущих специалистов факультета СПО в БелГАУ и других учреждений СПО Белгородской области.

Итогом изучения курса стала дискуссия на тему «Почему человек выбирает профессию педагога, преподавателя» или «Зачем нужна специальность педагога в учреждении СПО аграрного профиля».

В ходе практических занятий студенты получают задания, ответы на которые заставляют их определить и корректировать собственную позицию.

Например:

Задание 1. Продолжсите и аргументируйте ряд основньх требований к личности педагога будущего: профессиональная компетентность, интеллигентность, конкурентоспособность, духовность...

Задание 2. Подготовьте эссе на тему «Развитие профессионально-педагогической специальности в течение 20, 50, 100 лет» (письменно).

На практических занятиях по дисциплине «Педагогическое мастерство» студенты 1 курса выполняют задания, направленные не только на формирование педагогических умений и навыков, но и на формирование индивидуального облика, личностной ценностной позиции педагога.

Например, студенты выполняют задания, заставляющие их размышлять о ценности педагогической профессии и ценностных ориентациях учителя, о том, что передает учитель своим ученикам, чему и как их учит.

Приведем пример такого задания.

Задание 3. Просмотрите (вспомните) фрагменты из кинофильмов «Дожсивем до понедельника», «Учитель года», «Республика ШКИД», «Чучело», «Уроки франиузского», «Большая перемена» и др. и ответьте на следующие вопросы:

1. Какие общечеловеческие и педагогические ценности проявляет учитель в урочной и внеурочной деятельности?

2. В чем проявляется мастерство учителя на уроке и во внеурочной деятельности?

3. Что характерно для индивидуального стиля учителя? Что помогает ему в решении практических задач?

4. Как проявляется профессионально-педагогическая культура в поведении и деятельности педагога?

5. В чем причина успеха или неуспеха разных педагогов?

Студенты 2 курса изучают дисциплину «Психология профессиональной деятельности», которая занимает важное место в психолого-педагогической подготовке специалиста, поскольку приобретаемые знания и умения - основа усвоения методических дисциплин, более того, они имеют самостоятельное значение в будущей профессиональной деятельности. На занятиях студенты раскрывают такие понятия, как «профессия», «профессиональное становление», «профессиография», «профессиональная пригодность» и др. 
В то же время изучение этой дисциплины позволяет еще раз обратить внимание студентов на ценностный характер педагогической деятельности, на компоненты профессиональной культуры педагога, связанные со знанием и пониманием психологии обучающихся. Это такие компоненты, как понимание ценности человеческой личности, умение понять психологические особенности деятельности обучающихся, их реакции на действия педагога.

Одним из средств формирования психологической компетентности является решение психологических задач.

Например:

- Приведите убедительные аргументы «за» или «против» этого утверждения.

«Особенность деятельности педагога заключается в том, что лучшим орудием воспитания является он сам. Поэтому, как бы ни были развиты профессиональные качества, какими бы знаниями и умениями ни обладал педагог, подлинным воспитателем становится тот, кто способен оказывать позитивное нравственное влияние на развивающуюся личность» [Онушкин и др., 1987, с. 16].

Такая дисциплина, как «Моделирование психологической деятельности» носит чисто практический характер. Семинарские занятия по этой дисциплине на 3 курсе позволяют решать ряд задач, среди которых такие:

- ознакомление студентов с возможностями психологии и педагогики для успешного решения проблем жизни и профессиональной деятельности;

- содействие гуманитарному развитию студентов: психологического и педагогического мышления, наблюдательности, культуры их отношения к людям, общения и поведения [Любимова, 2016].

Особенностью подготовки, организации и проведения семинарских занятий по дисциплине «Моделирование психолого-педагогической деятельности» является то, что каждое занятие предполагает групповую работу, направленную на развитие рефлексивнотворческих способностей. Это позволяет студенту овладевать умением строить гипотезы, оперативно находить выход из сложившихся педагогических ситуаций, адекватно интерпретировать результаты взаимодействия участников педагогического процесса.

Основной прием на таком занятии - решение психолого-педагогических задач, в основе которых лежат реальные педагогические ситуации.

В процессе разрешения педагогической ситуации студент полностью включается в педагогическую деятельность, происходит осознание им профессионального выбора.

Педагогическая ситуация 1.

Обучаюшийся недоволен оченкой его работь и в качестве протеста влезает во время занятия на стол. В аудитории раздается смех, что вызывает нарушение рабочей обстановки. Продолжить занятие невозможно. Как купировать скандал? Какими путями можно было избежать такой ситуации? Как вернуть рабочую обстановку, если такой случай произошел?

Педагогическая ситуация 2.

Идет занятие, преподаватель объясняет новую тему, но обучаюшийся не слушает его: он увлечен смартфоном.

Эту проблему можно решить так: «Илья (или как зовут студента), давай договоримся. Ты сейчас уберешь телефон, так как мне надо продолжить новую тему, на следующем уроке ты будешь вместе со всеми писать по ней контрольную, и я не думаю, что ты сумеешь получить хорошую оченку, если сейчас пропустишь мои объяснения. А мне бы очень хотелось, чтобы у тебя была отличная оценка по моему предмету, да и твоим родителям это было бы очень приятно. А ты как считаешь?»

Формированию ценностных ориентаций общечеловеческого характера (здоровье и счастье других, забота о слабых, забота о красоте природы), несомненно, способствует включение первокурсников в волонтерскую деятельность, широко развитую в БелГАУ. 


\section{2. Включение студентов в систему практико-ориентированного обучения.}

Мотивации студентов к совершенствованию в педагогической деятельности, формированию всех компонентов профессионально-педагогической культуры может способствовать общий подход к организации всей учебной деятельности. Таким подходом, по нашему мнению, могут и должны быть контекстный подход [Вербицкий, 1981, 1991, 2004] и дуальное обучение [Petrosky, 2016].

Обращение к дуальному и контекстному обучению позволяет осуществить практико-ориентированное обучение. Для этого нужно, как пишет А.А. Вербицкий, «делая одно, учась, научиться принципиально иному - работать» [Вербицкий, 1991, с. 61].

В системе СПО принято апробированное в Германии дуальное обучение [Petrosky, 2016]. Однако подготовка к будущей педагогической деятельности требует обращения к «знаково-контекстному», или контекстному, обучению. А.А. Вербицкий связывал его появление «с появлением деловых игр и других ориентированных на практику форм и методов активного обучения в вузе» [Вербицкий, 1981, с. 20].

Контекстное преподавание - это образовательный процесс, цель которого помочь обучающемуся увидеть смысл в изучаемом материале, найти его связи с контекстом своей личной, социальной, профессиональной и культурной жизни. «Контекстное преподавание и учение вовлекает студентов в значимую для них деятельность, способствующую связи академического знания с контекстом ситуаций реальной жизни» [Johnson, 2002, с. 3].

Сущность контекстного обучения - создание психологических, педагогических и методических условий трансформации учебной деятельности в профессиональную с постепенной сменой потребностей и мотивов, целей, действий (поступков), средств, предмета и результатов деятельности. Для этого в формах учебной деятельности студентов последовательно моделируется профессиональная деятельность специалиста со стороны ее предметно-технологических (предметный контекст) и социальных (социальный контекст) составляющих, реализуется движение деятельности студента от учебной деятельности академического типа через квазипрофессиональную и учебно-профессиональную деятельности к деятельности собственно профессиональной.

В процессе обучения у студентов должны быть выработаны общий мотивационный синдром учения; познавательный мотивационный синдром; профессиональный мотивационный синдром [Вербицкий, Бакшаева, 2000]. В нашем же случае сложность заключается в том, что, помимо получения профессии агрария, студент должен быть мотивирован к получению профессии педагога, то есть должен быть выработан профессиональнопедагогический мотивационный синдром учения. Следовательно, в собственно учебную, квазипрофессиональную, учебно-профессиональную деятельности студентов должен быть включен профессионально-педагогический компонент.

Контекстное обучение - обучение активное, предполагающее использование таких форм и методов организации процесса обучения, которые его не просто регламентируют, алгоритмизируют, программируют, а делают его развивающим, проблемным, исследовательским, поисковым, обеспечивающим рождение познавательных мотивов и интересов, создают условия для творчества в процессе обучения [Клименко, 2014].

Для БелГАУ в аграрном педагогическом кластере Белгородского региона существует хорошая база для контекстного обучения будущих педагогов учреждений СПО аграрного профиля - это факультет СПО при самом БелГАУ, 12 учреждений СПО - техникумов и колледжей, расположенных в районных центрах Белгородской области: Алексеевка, Бирюч, Борисовка, Вейделевка, Короча, Новый Оскол, Ракитное, Старый Оскол, Чернянка, Шебекино, а также в селах Дмитриевка Ракитянского района и Ютановка Волоконовского района Белгородской области [Никулина, 2018]. Во многих школах Белгородской области создаются аграрные классы в рамках движения «Доброжелательная школа», где дети будут получать начальное аграрное образование. 
Будущий педагог имеет возможность с первого года обучения педагогическому мастерству проходить пассивную педагогическую практику, то есть посещать занятия в учреждениях СПО. Студенты организуют встречи, дискуссии с ведущими педагогами СПО, посещают их мастер-классы, проводят пробные занятия, помогают в кураторской работе, организуют различные мероприятия со студентами учреждений СПО.

Благодаря этому, к педагогической практике студенты приходят подготовленными к осуществлению преподавательской деятельности, чувствуют себя уверенно.

Формированию профессиональной компетентности будущего специалиста, то есть профессионально-педагогического и технологического компонентов профессиональнопедагогической культуры педагога, будет способствовать привлечение наиболее апробированных в современной педагогической практике концептуальных подходов:

- компетентностного (А.А. Дахин, И.А. Зимняя, Г.А. Ларионова, Г.К. Селевко, В.В. Сериков, А. В. Хуторской и др.), рекомендованного ФГОС ВПО, глубоко разработанного и широко применяемого в современной системе подготовки специалистов, позволяющего формировать компетенции, связанные с общечеловеческой и национальной культурой: общекультурные (ОК), общие профессиональные (ОП) и специальные (СП); сформированность профессиональной компетентности является одним из обязательных компонентов профессионально-педагогической культуры (В.А. Бодров, Е.А..Климов, А.К. Маркова, Л.М. Митина, Ю.П. Поваренков, Н.С. Пряжников, М.А. Чошанов и др.);

- личностно ориентированного (Н.А. Алексеев, Е.В. Бондаревская, Л.М. Кустов, Г.К Селевко, В.В. Сериков, А.В. Хуторской, И.С. Якиманская и др.), направленного на развитие личности студента в процессе обучения, установление субъект-субъектных отношений, придание творческого характера всему процессу подготовки педагога;

- деятельностного (Л.С. Выготский, И.А. Зимняя, А.Н. Леонтьев, Л.С. Рубинштейн, А.В. Хуторской и др.), который требует обучать профессии в деятельности - учебной, учебно-профессиональной, квазипрофессиональной, профессиональной, любой деятельности, способствующей практико-ориентированному обучению.

\section{3. Ознакомление студентов с основами педагогической герменевтики.}

О ценности герменевтического подхода в образовании, пока мало описанного в специальной литературе, утверждающего, что обучение и воспитание возможны только через понимание преподавателем студента, а студентом преподавателя, говорили многие ученые: В.И. Андреев [2012], Б.М. Бим-Бад [2017], З.Ф. Закирова [2011; 2012], Л.А. Орлова [2014] и др. Педагог должен понимать студента «интеллектуально, социально, культурно и личностно в перспективе развития» [Shulman, 2004, с. 262]. Понимание достигается путем изучения учащегося, осмысления его проблем, признания значимости и уникальности его личности, принятия его как ценности [Орлова, 2014]. Понимающее мышление - профессионально важное качество мышления каждого педагога. Понимание осуществляется через вчувствование, вживание, проникновение во внутренний мир обучающегося, создание модели его в своем воображении.

Педагогическая герменевтика получила свое развитие в XX в. Веком раньше Ф. Шлейермахер утверждал, что понимание осуществляется в соответствии с определенной техникой, и этой технике можно и нужно учить, что понимание является непременным атрибутом образования, его составной частью и теснейшим образом связано с мышлением и речью [Шлейермахер, 2004, с. 46-48]. Понятие педагогической герменевтики определено и описано 3.Ф. Закировой, она убеждена, что сферой ее применения является профессиональное образование [Закирова, 2011]. В.И. Андреев выделяет герменевтический метапринцип, способствующий целостному пониманию культурных общечеловеческих ценностей, творческому саморазвитию личности в процессе получения образования [Андреев, 2012]. Л.А. Орлова считает понимание ключевой характеристикой мышления учителя [Орлова, 2014]. Сегодня герменевтика - важнейшая составляющая педагогического процесса. 
Этот подход способствует формированию коммуникативной компетентности и рефлексивной культуры педагога, без которых невозможно взаимопонимание педагога и учащегося, а следовательно, и их активное и продуктивное взаимодействие.

Компонентом профессионально-педагогической культуры педагога, феноменом, «в основе которого лежит система гуманистических ценностей и смыслов» педагогического общения, является коммуникативная культура [Shishova, 2015, с. 345]. Она «базируется на системе гуманистических ценностей» и предполагает владение искусством взаимодействия с обучаемым [Любимова, 2018]. Коммуникативная культура - это не только нормативный набор вербальных и невербальных навыков, но и духовно-нравственная деятельность человека в процессе создания коммуникативного акта [Shishova, 2015, с. 345]. Учеными определено место коммуникативной компетенции в профессиограмме педагога как компетенции, без которой невозможно формирование ни одной из профессиональных компетенций [Игнатова, Ильенко, 2015]. Особое значение придается интонационно-речевому воздействию, поскольку изменение тона, тембра, темпа речи вызывает немедленную спонтанную реакцию и обучающегося, и педагога [Ильенко, 2016].

Д. Уесли сформулировал 11 положений, «ожиданий», достижение которых и их соблюдение необходимо каждому педагогу, желающему стать Великим. При этом на первое место он поставил способность педагога сопереживать - эмпатию [Wesley, 1998].

Алгоритм педагогического взаимодействия имеет следующую структуру (рис. 2):

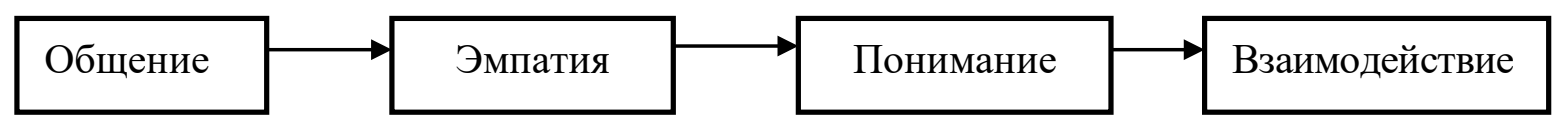

Рис. 2. Алгоритм педагогического взаимодействия

Fig. 2. Algorithm of pedagogical interaction

Одной из составляющих профессионально-педагогической культуры будущих педагогов следует признать рефлексивную культуру педагога, представляющую собой интегративное, динамическое образование личности, которое включает в себя овладение комплексом рефлексивных знаний и умений, способов самопознания, самооценки, выработку установки на ценностное отношение к предстоящей профессиональной деятельности и на развитие профессионально личностных качеств.

Формирование рефлексивной культуры педагога также предполагает создание педагогических условий, таких как специально организованная рефлексивная деятельность педагога; наличие рефлексивной среды; активизация межсубъектных отношений между участниками рефлексивной деятельности; актуализация рефлексивности педагога.

\section{Заключение}

Анализ тестирования студентов по итогам трехлетнего обучения позволил сделать вывод о том, что избранный нами путь формирования профессионально-педагогической культуры будущих педагогов учреждений СПО аграрного профиля правилен, рационален, эффективен. Более 80 \% прошедших обучение студентов заявили о желании стать педагогами, на первых местах среди ценностей появилась интересная работа и творчество, 810 места заняли забота о других и красота природы.

Проведенное исследование позволило сделать следующие выводы.

Формирование профессионально-педагогической культуры будущего педагогаагрария - длительный и ответственный процесс, сопряженный с глубокой перестройкой личности студента, коррекцией его ценностных ориентаций, профессионализацией его 
сознания, мотивацией всей его деятельности и развития, направленностью их на приобретение педагогических компетенций.

Ведущую роль в профессиональной ориентации, в направленной практикоориентированной подготовке педагога-агрария играет контекстный подход к организации всего процесса обучения и воспитания в вузе.

Привлечение герменевтического подхода, обретение способности понимать обучающегося позволяет будущему педагогу почувствовать себя уверенно в любой аудитории, помогает находить общий язык с обучаемыми и коллегами по работе, делает молодого специалиста более коммуникабельным.

Таким образом, мы убедились, что нами выбран правильный, наиболее рациональный подход к подготовке будущего педагога-агрария, востребованного в аграрном образовательном кластере Белгородского региона. Наш педагогический эксперимент, на наш взгляд, можно признать удачным и заслуживающим быть предложенным для ознакомления коллегам из других вузов.

\section{Список источников}

1. Андреев В.И. 2012. Педагогика: учебный курс для творческого саморазвития. Казань, Издательство «Центр инновационных технологий», 608 с.

2. Бим-Бад Б.М. 2017. Педагогическая антропология: учебник и практикум для академического бакалавриата. М.: Издательство Юрайт, 223 с.

3. Борытко Н.М., Моложавенко А.В., Соловцова И.А. 2006. Методология психологопедагогических исследований: учеб. для магистров и студ. пед. вузов. Волгоград: ВГПУ, 320 с.

4. Веденяпина В.А. 2003. Профессиональная культура учителя: учеб. пособие для студентов вузов. Борисоглебск: ООО Кристина и К., 163 с.

5. Зеер Э.Ф. 2015. Психология профессий: учебное пособие для студентов вузов. М.: Академический Проект, Фонд «Мир», 336 с. URL: http://www.iprbookshop.ru/36853.html. — ЭБС «IPRbooks».

6. Маркова А.К. 1996. Психология профессионализма: Пособие. М.: Международный гуманитарный фонд «Знание», 308 с.

\section{Список литературы}

1. Батракова С.Н. 2004. Динамика профессиональных функций педагога как представителя культуры. Ярославский психологический вестник, 2: 71-77.

2. Вербицкий А.А. 1981. Выступление на круглом столе «Психология и педагогика высшей школы: проблемы, результаты, перспективы». Вопросы психологии, 3: 17-21.

3. Вербицкий А.А. 1991. Активное обучение в высшей школе: контекстный подход. М., Высшая школа, 207 с.

4. Вербицкий А.А. 2004. Компетентностный подход и теория контекстного обучения. М., Исследовательский центр проблем качества подготовки специалистов, $84 \mathrm{c.}$

5. Вербицкий А.А., Бакшаева Н.А. 2000. Развитие мотивации студентов в контекстном обучении. М., Исследовательский центр проблем качества подготовки специалистов, 200 с.

6. Драгунова О.Н. 2012. Формирование мотивационно-ценностного отношения будущих социальных педагогов к профессиональной деятельности. Автореф. дис. ... канд. пед. наук. Москва, 25 с.

7. Закирова А.Ф. 2011. Педагогическая герменевтика: концептуальные основания, социокультурное значение, область применения. В кн.: Специфика педагогического образования в регионах России. Материалы IV-й Всероссийской научно-практической конференции с участием ближнего и дальнего зарубежья, Тюмень - Санкт-Петербург, 22 октября 2010 года. Под ред. О.В Ройблат, Н.Г. Миловановой, Н.Н. Суртаевой. Тюмень, Тюменский областной государственный институт развития регионального образования: 15-20.

8. Закирова А.Ф. 2012. Теоретические основы педагогической герменевтики и варианты ее реализации в научно-образовательной практике. Образование и наука, 6 (95) 19-42. 
9. Игнатова И.Б., Ильенко Н.М. 2015. Место коммуникативной компетенции в профессиограмме педагога. Образование и общество, 6 (95): 42-46.

10. Ильенко Н.М. 2016. Значение интонационно-речевого воздействия в педагогической коммуникации. В кн.: Наука. Культура. Искусство. Актуальные проблемы теории и практики. Сборник докладов Всероссийской научно-практической конференции, г. Белгород, 25-26 февраля 2016 года. В 4-х т. Т. 4. Под ред. С.Н. Борисова. Белгород, ИПК БГИИК: 212-220.

11. Исаев И.Ф. 2002. Профессионально-педагогическая культура преподавателя высшей школы как саморазвивающаяся система. Гаудеамус, 1 (1): 20-30.

12. Исаев И.Ф. 2004. Профессионально-педагогическая культура преподавателя. М., Издательский центр «Академия», 208 с.

13. Клименко И.В. 2014. Динамика мотивационно-ценностной направленности студентов на профессиональную деятельность. Дис. ... канд. психол. наук. Москва. 243 с.

14. Любимова Н.И. 2016. Моделирование психолого-педагогической деятельности педагога. Белгород, Изд-во БГАУ, 66 с.

15. Любимова Н.И. 2018. Формирование опыта педагогического взаимодействия у будущих преподавателей системы среднего профессионального образования. Научные ведомости Белгородского государственного университета. Серия: Гуманитарные науки, 37 (2): 312-320.

16. Маркова А.К. 1996. Психология профессионализма. М.: Международный гуманитарный фонд «Знание», 308 с.

17. Никулина Н.Н. 2018. Совершенствование профессионального образования как условие успешного развития инновационных агропроектов. Научный результат. Педагогика и психология образования, 4 (4): 73-82. DOI: 10.18413/2313-8971-2018-4-4-0-7.

18. Онушкин В.Г., Кулюткин Ю.Н., Вершловский С.Г. 1987. Профессия учитель: беседы с молодыми учителями. Под ред. В.Г. Онушкина, Ю.Н. Кулюткина, С.Г. Вершловского. М., Педагогика, 192 с.

19. Орлова Л.А. 2014. Понимание как ключевая характеристика мышления учителя. Гуманитарные ведомости ТГПУ им. Л.Н. Толстого, 1 (9): 61-66.

20. Путивцев П.В. 2014. Формирование психологической готовности студентов к профессиональной деятельности. Вестник МГОУ. Серия: Психологические науки, 1: 114-122.

21. Шлейермахер Ф. 2004. Герменевтика. СПб.: Европейский дом, 242 с. URL: https://yadi.sk/i/B2UVwGCOkPSh3 (дата обращения: 16.02.2019).

22. Husu J. 2004. Negotiating the shared educational beliefs and values of a schools social curriculum. In: European Conference on Educational Research, University of Crete, 22-25 September 2004. Available: http://www.leeds.ac.uk/educol/documents/00003717.htm (accessed: 13.03.2020).

23. Johnson E.B. 2002. Contextual Teaching and Learning: What It Is and Why It's Here To Stay. Corwin Press, Inc., A Sage Publications Company, Teller Road, Thousand Oaks, CA, 211 p.

24. Petrosky J. 2016. The German Dual Educational System: Evolving Needs for a Skilled Workforce. A unified Germany in federal Evropa, 14. Available: https://preserve.lehigh.edu/perspectives-v14/ (accessed: 20.03.2020).

25. Rokeach M. 1968. Beliefs, Attitude and Values. San Francisco, Jossey-Bass, 214 p.

26. Shishova E. O. 2015. Communicative Culture as a Component of Professional Competence of Future Teachers in the Bilingual Environment. Mediterranean Journal of Social Sciences, 6 (3): 344349.

27. Shulman L.S., Shulman J.H. 2004. How and what teachers learn: A shifting perspective. Journal of Curriculum Studies, 36 (2): 257-271. DOI: doi.org/10.1080/0022027032000148298.

28. Wesley D.C. 1998. Eleven Ways to Be a Great Teacher. Strengthening the Teaching Profession, 55 (5): 80-81.

\section{References}

1. Batrakova S.N. 2004. Dinamika professional'nykh funktsiy pedagoga kak predstavitelya kul'tury [Dynamics of professional functions of a teacher as a representative of culture]. Yaroslavskiy psikhologicheskiy vestnik, 2: 71-77.

2. Verbitskiy A.A. 1981. Vystuplenie na kruglom stole «Psikhologiya i pedagogika vysshey shkoly: problemy, rezul'taty, perspektivy» [Speech at the round table "Psychology and pedagogy of higher education: problems, results, prospects"]. Voprosy Psychologi, 3: 17-21. 
3. Verbitskiy A.A. 1991. Aktivnoe obuchenie v vysshey shkole: kontekstnyy podkhod [Active Learning in Higher Education: A Contextual Approach]. M., Publ. Vysshaya shkola, 207 p.

4. Verbitskiy A.A. 2004. Kompetentnostnyy podkhod i teoriya kontekstnogo obucheniya [Competence approach and contextual learning theory]. M., Publ. Issledovatel'skiy tsentr problem kachestva podgotovki spetsialistov, $84 \mathrm{p}$.

5. Verbitskiy A.A., Bakshaeva N.A. 2000. Razvitie motivatsii studentov v kontekstnom obuchenii [Development of student motivation in contextual learning]. M., Publ. Issledovatel'skiy tsentr problem kachestva podgotovki spetsialistov, $200 \mathrm{p}$.

6. Dragunova O.N. 2012. Formirovanie motivatsionno-tsennostnogo otnosheniya budushchikh sotsial'nykh pedagogov k professional'noy deyatel'nosti [Formation of the motivational-value attitude of future social teachers to professional activity.]. Abstract. dis. ... cand. ped. sciences. Moskva, 25 p.

7. Zakirova A.F. 2011. Pedagogicheskaya germenevtika: kontseptual'nye osnovaniya, sotsiokul'turnoe znachenie, oblast' primeneniya [Pedagogical hermeneutics: conceptual foundations, sociocultural significance, scope]. In: Spetsifika pedagogicheskogo obrazovaniya v regionakh Rossii [Specificity of teacher education in the regions of Russia]. Materials of the IVth all-Russian scientific and practical conference with the participation of near and far abroad, Tyumen - Saint Petersburg, October 22, 2010. Eds. O.V Royblat, N.G. Milovanovoy, N.N. Surtaevoy. Tyumen', Publ. Tyumenskiy oblastnoy gosudarstvennyy institut razvitiya regional'nogo obrazovaniya: 15-20.

8. Zakirova A.F. 2012. Teoreticheskie osnovy pedagogicheskoy germenevtiki i varianty ee realizatsii v nauchno-obrazovatel'noy praktike [Theoretical foundations of pedagogical hermeneutics and options for its implementation in scientific and educational practice]. The Education and Science, 6 (95) 19-42.

9. Ignatova I.B., Il'enko N.M. 2015. Mesto kommunikativnoy kompetentsii v professiogramme pedagoga [The place of communicative competence in the teacher's professiogram]. Obrazovanie i obshchestvo, 6 (95): 42-46.

10. Il'enko N.M. 2016. Znachenie intonatsionno-rechevogo vozdeystviya v pedagogicheskoy kommunikatsii [The value of intonation and speech influence in pedagogical communication.]. In: Nauka. Kul'tura. Iskusstvo. Aktual'nye problemy teorii i praktiki [The science. Culture. Art. Actual problems of theory and practice]. Collection of reports of the all-Russian scientific and practical conference, Belgorod, February 25-26, 2016. In 4 volumes. Vol. 4. Ed. S.N. Borisova. Belgorod, Publ. IPK BGIIK: 212-220.

11. Isaev I.F. 2002. Professional'no-pedagogicheskaya kul'tura prepodavatelya vysshey shkoly kak samorazvivayushchayasya sistema [Professional and pedagogical culture of a higher school teacher as a self-developing system]. Gaudeamus, 1 (1): 20-30.

12. Isaev I.F. 2004. Professional'no-pedagogicheskaya kul'tura prepodavatelya [Professional and pedagogical culture of the teacher]. M., Publ. "Akademiya", 208 p.

13. Klimenko I.V. 2014. Dinamika motivatsionno-tsennostnoy napravlennosti studentov na professional'nuyu deyatel'nost' [Dynamics of students' motivational-value orientation towards professional activity]. Dis. ... cand. psychol. sciences. Moscow, 243 p.

14. Lyubimova N.I. 2016. Modelirovanie psikhologo-pedagogicheskoy deyatel'nosti pedagoga [Modeling the psychological and pedagogical activity of a teacher]. Belgorod, Publ. BGAU, 66 p.

15. Lyubimova N.I. 2018. Formirovanie opyta pedagogicheskogo vzaimodeystviya u budushchikh prepodavateley sistemy srednego professional'nogo obrazovaniya [Formation of experience of pedagogical interaction among future teachers of the secondary vocational education]. Scientific bulletin of Belgorod State University. Humanities Series, 37 (2): 312-320.

16. Markova A.K. 1996. Psikhologiya professionalizma. [Psychology of professionalism]. M.: Merzdunarodnyj gumanitarnyj fond "Znaniye”, 308 p.

17. Nikulina N.N. 2018. Sovershenstvovanie professional'nogo obrazovaniya kak uslovie uspeshnogo razvitiya innovatsionnykh agroproektov [Improving vocational education as a condition for the successful development of innovative agricultural projects]. Research result. Pedagogy and Psychology of Education, 4 (4): 73-82. DOI: 10.18413/2313-8971-2018-4-4-0-7.

18. Onushkin V.G., Kulyutkin Yu.N., Vershlovskiy S.G. 1987. Professiya uchitel': besedy s molodymi uchitelyami [Teaching profession: conversations with young teachers.]. Eds. V.G. Onushkin, Yu.N. Kulyutkin, S.G. Vershlovskiy. M., Publ. Pedagogika, 192 p.

19. Orlova L.A. 2014. Ponimanie kak klyuchevaya kharakteristika myshleniya uchitelya [Understanding as a key characteristic of the teacher's thinking]. Gumanitarnye vedomosti TGPU im. L.N. Tolstogo, 1 (9): 61-66. 
20. Putivtsev P.V. 2014. Formirovanie psikhologicheskoy gotovnosti studentov k professional'noy deyatel'nosti [Formation of psychological readiness of students for professional activity]. Bulletin of the Moscow Region State University. Series: Psychology, 1: 114-122.

21. Schleiermacher F. 2004. Germenevtika [Hermeneutics]. SPb.: Evropeyskiy dom, 242 s. URL: https://yadi.sk/i/B2UVwGCOkPSh3 (accessed: 16.02.2019).

22. Husu J. 2004. Negotiating the shared educational beliefs and values of a schools social curriculum. In: European Conference on Educational Research, University of Crete, 22-25 September 2004. Available at: http://www.leeds.ac.uk/educol/documents/00003717.htm (accessed: 13.03.2020).

23. Johnson E.B. 2002. Contextual Teaching and Learning: What It Is and Why It's Here To Stay. Corwin Press, Inc., A Sage Publications Company, Teller Road, Thousand Oaks, CA, 211 p.

24. Petrosky J. 2016. The German Dual Educational System: Evolving Needs for a Skilled Workforce. A unified Germany in federal Evropa, 14. Available at: https://preserve.lehigh.edu/perspectivesv14/ (accessed: 20.03.2020).

25. Rokeach M. 1968. Beliefs, Attitude and Values. San Francisco, Jossey-Bass, 214 p.

26. Shishova E. O. 2015. Communicative Culture as a Component of Professional Competence of Future Teachers in the Bilingual Environment. Mediterranean Journal of Social Sciences, 6 (3): 344349.

27. Shulman L.S., Shulman J.H. 2004. How and what teachers learn: A shifting perspective. Journal of Curriculum Studies, 36 (2): 257-271. DOI: doi.org/10.1080/0022027032000148298.

28. Wesley D.C. 1998. Eleven Ways to Be a Great Teacher. Strengthening the Teaching Profession, 55 (5): 80-81.

\section{ИНФОРМАЦИЯ ОБ АВТОРАХ}

Любимова Наталья Ивановна, кандидат педагогических наук, доцент кафедры профессионального обучения и социальнопедагогических дисциплин Белгородского государственного аграрного университета им. В.Я. Горина, г. Белгород, п. Майский, Россия

Никулина Наталья Николаевна, кандидат педагогических наук, доцент, заведующая кафедрой профессионального обучения и социально-педагогических дисциплин Белгородского государственного аграрного университета им. В.Я. Горина, г. Белгород, п. Майский, Россия

\section{INFORMATION ABOUT THE AUTHORS}

Natalya I. Lyubimova, Candidate of Pedagogical Sciences, Associate Professor of the Department of Professional Education and Social and Pedagogical Disciplines, Belgorod State Agrarian University V. Ya. Gorin, Belgorod, Mayskiy, Russia

Natalya N. Nikulina, Candidate of Pedagogical Sciences, Associate Professor, Head of the Department of Vocational Training and Social and Pedagogical Disciplines, Belgorod State Agrarian University V.Ya. Gorin, Belgorod, Maisky, Russia 